\title{
Prevalence and haematological parameters for bovine viral diarrhoea (BVD) in south Bengal areas in Bangladesh
}

\author{
MMR Chowdhury*, F Afrin'1, SS Saha², S Jhontu and MA Asgar \\ Department of Physiology and Pharmacology, Patuakhali Science \& Technology \\ University, Patuakhali, Bangladesh
}

\begin{abstract}
A total of 94 blood samples were collected from commercial dairy farms, from 6 Upazillas of Barisal division. The prevalence of Bovine Viral Diarrhoea Virus (BVDV) in south Bengal areas was $51.1 \%$, the maximum prevalence was in Ujirpur Upazilla (Sub-district; $100 \%)$ and the lowest in Pirojpur Upazilla $(13.6 \%)$. There was significant $(\mathrm{P}<0.05)$ variation in the prevalence between farms. Prevalence was highest $(61.3 \%)$ in animals between 3 and 5 years of age, and lowest $(31.8 \%)$ in $0-1$ year-old animals. Animals with low body condition score (BCS-2) had higher $(63.6 \%)$ prevalence in comparison to animals of high BCS-3.5. Haemoglobin $(\mathrm{Hb})$ was $8.7 \pm 0.1 \mathrm{gm} \%$ compared to $8.6 \pm 0.1 \mathrm{gm} \%$. Lymphocyte count was significantly $(\mathrm{P}<0.05)$ higher $(64.1 \pm 0.3 \%)$ in BVD-positive animals than negative animals $(41.8 \pm 1.2 \%)$. The neutrophil count was significantly $(\mathrm{P}<0.05)$ higher in BVD-positive animals $(22.1 \pm 0.5 \%)$ compared to negative animals $(16.9 \pm 0.5 \%)$. Other haematological parameters were not significantly different. (Bangl. vet. 2015. Vol. 32, No. 2, $48-54)$
\end{abstract}

\section{Introduction}

Bovine viral diarrhoea virus (BVDV) belongs to the family Flaviviridae and the genus Pestivirus (ICTV, 2011). The virus is classified into non-cytopathogenic (ncp) and cytopathogenic (cp) based on the effects it produces on the bovine cell culture. On the basis of antigenic and genetic features, BVDV is classified into two species- BVDV-1 and BVDV-2. BVDV-1 is dominant in North America and BVDV-2 in Europe, where it comprises above $90 \%$ of cases (Lindberg et al., 2006). Disease occurs significantly with BVDV-1 although outcomes have been mainly described after infection with BVDV-2. It causes poor reproductive performance in cows and mucosal disease in calves (Mishra et al., 2009). The characteristic clinical signs are leucopenia, transient fever, diarrhoea, abortion, respiratory distress, reproductive failure and congenital defects in calves (Lucero et al., 2006), lameness, early embryonic death and immune suppression (Rubaye and Hasso, 2012), mummification, stillbirth, neural defects and calving of persistently infected calves (Ahmad et al., 2011). In Bangladesh, very few records are available on the prevalence of the disease in dairy herds (Samad, 1999;

\footnotetext{
1Department of Microbiology and Hygiene, Faculty of Veterinary Science, Bangladesh Agricultural University, Mymensingh-2202, Bangladesh

2Department of Pathology and Parasitology, Patuakhali Science \& Technology University, Patuakhali, Bangladesh

*Corresponding author:- E-mail: mustafizbof@gmail.com
} 
Haider et al., 2013). The present study was carried out to determine the prevalence of BVDV and haematological changes in the commercial dairy herds in Barisal division.

\section{Materials and Methods}

The study was carried out in the Department of Physiology and Pharmacology, Patuakhali Science and Technology University and Field Disease Investigation Laboratory (FDIL), Barisal Head Quarter (Sadar) from July 2013 to April 2014.

\section{Sample size and diagnosis of the disease}

A total of 94 blood samples were collected from commercial dairy farms, from 6 Upazillas of Barisal division. Prevalence of BVD was confirmed on the basis of clinical history and the laboratory analysis of blood samples. Blood samples $(2 \mathrm{~mL}$ each) were collected through jugular veni puncture using $5 \mathrm{~mL}$ disposable plastic syringe with 19G needle from adult and young non-vaccinated healthy and persistent diarrhoeal cattle (Archambault et al., 2000; Hamers et al., 2000; Stoffregen et al., 2000; LieblerTenorio et al., 2002).

After collection, blood sample was taken into a cryovial containing anticoagulant (EDTA $0.2 \%$; Merck, Germany) for further use.

\section{Haematology}

EDTA-mixed blood (2 mL) was used to determine total erythrocyte count (TEC), haemoglobin $(\mathrm{Hb})$, packed cell volume $(\mathrm{PCV})$, total leukocyte count (TLC) as described by Jain (1986). Differential leukocyte counts were estimated using Wrightstained blood smears (Jain, 1986).

\section{Statistical analysis}

Differential leukocyte Count (DLC) was analysed in control and affected animals using SPSS version 18.0 for windows (Statistical Package for the Social Sciences, SPSS Inc., Chicago, IL, USA) and graphs were prepared using Sigma Plot 10. Student T-test was performed to compare TEC, TLC, PCV, haemoglobin, and the Pearson Chi-square test was used to detect the BVDV in dairy farms, types of animals, age groups, BCS and diarrhoeic and non-diarrhoeic animals. A $p$ value of $\leq 0.05$ was considered statistically significant.

\section{Results and Discussion}

The prevalence of BVDV in the Barisal Division was 51.1\% (Table 1: the highest prevalence was in Ujirpur Upazilla $(100 \%)$ and the lowest in Pirojpur Upazilla $(13.6 \%)$. However, the number of the samples in Ujirpur (3) was low. Larger sample size may show different results). Similar observation was recorded in north Italy (Luzzago et al., 1999). In Turkey a higher prevalence (60\%) was observed (Gelfert, 
1991; Sudharshana et al., 1999) and about 15.3\% in India, which is similar to the lowest value in the present study $(13.6 \%)$.

Table 1. Prevalence of BVDV in the different Upazillas of Barisal division

\begin{tabular}{c|c|c|c}
\hline SL. No. & Name of Upazillas & No. of Cases & Positive \\
\hline $\mathbf{1}$ & Sadar (Head Quarter) & 17 & $5(29.4 \%)$ \\
$\mathbf{2}$ & Rahmatpur & 8 & $5(62.5 \%)$ \\
$\mathbf{3}$ & Babuganj & 15 & $8(53.3 \%)$ \\
$\mathbf{4}$ & Ujirpur & 3 & $3(100 \%)$ \\
$\mathbf{5}$ & Sharupkathi & 29 & $24(82.8 \%)$ \\
$\mathbf{6}$ & Pirojpur & 22 & $3(13.6 \%)$ \\
\hline \multicolumn{5}{r}{}
\end{tabular}

Table 2. Prevalence of BVDV in different types of animals: Percentage of diarrhoeic and non-diarrhoeic animals positive for BVDV

\begin{tabular}{c|cccc}
\hline SL. No. & Types of animals & No. of observations & Positive \\
\hline $\mathbf{1}$ & Diarrhoeic & 41 & $18(43.9 \%)$ \\
$\mathbf{2}$ & Non-diarrhoeic & 53 & $30(56.6 \%)$ \\
\hline
\end{tabular}

\section{Case record of $B V D V$ within the different age groups}

Prevalence of BVDV was highest in animals 3-5 years of age $(61.3 \%)$. Prevalence in calves was low (31.8\%: Table 3$)$. The differences were not significant.

Table 3: Prevalence of BVDV in various age groups of animals

\begin{tabular}{c|c|c|c}
\hline SL No. & Age of Animals (Year) & No. of cases & Positive \\
\hline 1 & $0-1$ & 22 & $7(31.8 \%)$ \\
2 & $>1-3$ & 21 & $10(47.6 \%)$ \\
3 & $>3-5$ & 31 & $19(61.3 \%)$ \\
4 & $>5$ & 20 & $12(60.0 \%)$ \\
\hline
\end{tabular}

\section{Prevalence of BVDV in dairy farms at different zones of Barisal}

In north zone, a total of 29 samples were collected from one farm, of which $24(82.8 \%)$ were positive, the highest. In south zone, 54 samples from three different farms were tested, of which $16(29.6 \%)$ (Table 4$)$ were positive, the lowest. The differences between these zones were significant $(\mathrm{P} \leq 0.05)$.

BVDV was highest $(63.6 \%)$ in animals with BCS-2 and lowest (38.5\%) in animals with BCS-3.5 (Table 5). The differences were not significant. 
Table 4. Regional prevalence of bovine viral diarrhoea virus seropositive cows

\begin{tabular}{c|c|c|c}
\hline SL. No. & Zones & No. of cases & Positive \\
\hline $\mathbf{1}$ & South & 54 & $16(29.6 \%)$ \\
$\mathbf{2}$ & Central & 11 & $8(72.7 \%)$ \\
$\mathbf{3}$ & North & 29 & $24(82.8 \%)$ \\
\hline
\end{tabular}

\section{Distribution of BVDV among animals of different Body Condition Score (BCS)}

Table 5. BCS and prevalence of BVDV in cattle

\begin{tabular}{c|c|c|c}
\hline SL. No. & BCS & No. of cases & Positive \\
\hline $\mathbf{1}$ & 2 & 22 & $14(63.6 \%)$ \\
$\mathbf{2}$ & 2.5 & 12 & $6(50.0 \%)$ \\
$\mathbf{3}$ & 3 & 47 & $23(48.9 \%)$ \\
$\mathbf{4}$ & 3.5 & 13 & $5(38.5 \%)$ \\
\hline
\end{tabular}

Comparison of different haematological parameters between BVDV positive and negative animals.

None of the haematological values showed significant variation (Table 6). In case of BVDV positive animals, total erythrocyte count (TEC) was $6.2 \pm 0.1$, whereas in BVDV negative animals the value was $6.3 \pm 0.1\left(\times 10^{6} / \mathrm{cu} \mathrm{mm}\right)$. Total leukocyte count (TLC) value of BVDV positive and negative animals were $8.6 \pm 0.4$ and $9.2 \pm 0.4\left(\times 10^{3} / \mathrm{cu}\right.$ $\mathrm{mm})$, respectively. The packed cell volume (PCV) was $(28.5 \pm 0.6)$ and $(27.9 \pm 0.7) \%$, respectively. Haemoglobin $(\mathrm{Hb})$ percentage was $8.7 \pm 0.1$ and $8.6 \pm 0.1 \%$ in case of BVDV positive and negative animals, respectively.

Table 6. Haematological values in BVDV positive and negative animals

\begin{tabular}{l|c|c}
\hline \multicolumn{1}{c|}{ Variables } & Diagnosis & Mean \pm SE \\
\hline TEC $(\times \mathbf{1 0} / \mathbf{c u ~} \mathbf{~ m m})$ & BVDV Positive & $6.2 \pm 0.1$ \\
& BVDV Negative & $6.3 \pm 0.1$ \\
TLC $(\times \mathbf{1 0} / \mathbf{c u ~ m m})$ & BVDV Positive & $8.6 \pm 0.4$ \\
& BVDV Negative & $9.2 \pm 0.4$ \\
PCV $(\mathbf{\%})$ & BVDV Positive & $28.5 \pm 0.6$ \\
& BVDV Negative & $27.9 \pm 0.7$ \\
$\mathbf{H b}(\mathbf{g} / \mathbf{d L})$ & BVDV Positive & $8.7 \pm 0.1$ \\
& BVDV Negative & $8.6 \pm 0.1$ \\
\hline
\end{tabular}

\section{Differential leukocyte count (DLC) in BVDV positive and negative animals}

In case of DLC, the only significant difference was in basophils. Lymphocyte count was $64.1 \pm 0.3 \%$ in BVD-positive and $41.8 \pm 1.2 \%$, in BVD-negative animals. Monocyte 
count was $5.6 \pm 0.1 \%$ in BVD-positive and $4.9 \pm 0.1 \%$ in BVD-negative animals. In BVD-positive animals the neutrophil count was $22.1 \pm 0.5 \%, 16.9 \pm 0.5 \%$ in BVDnegative animals. Eosinophil count was $9.7 \pm 0.1 \%$ in BVD-positive and $8.9 \pm 0.1 \%$, in BVD-negative animals. The basophil count was $0.6 \pm 0.0 \%$ in BVD-positive and $1.3 \pm$ $0.0 \%$ in BVD-negative animals (Table 7).

Table 7. Distribution of leukocytes in BVD-positive and negative animals

\begin{tabular}{lcc}
\hline \multicolumn{1}{c}{ Variables } & Diagnosis & Mean \pm SE \\
\hline Lymphocyte (\%) & BVD Positive & $64.1 \pm 0.3^{* *}$ \\
& BVD Negative & $41.8 \pm 1.2$ \\
Monocyte (\%) & BVD Positive & $5.6 \pm 0.1$ \\
& BVD Negative & $4.9 \pm 0.1$ \\
Neutrophil (\%) & BVD Positive & $22.1 \pm 0.5^{* *}$ \\
& BVD Negative & $16.9 \pm 0.5$ \\
Eosinophil (\%) & BVDV Positive & $9.7 \pm 0.1$ \\
Basophil (\%) & BVDV Negative & $8.9 \pm 0.1$ \\
& BDDV Positive & $0.6 \pm 0.0$ \\
& BVDV Negative & $1.3 \pm 0.0 *$ \\
\hline
\end{tabular}

**Statistically significant

The haemoglobin concentration was $8.7 \pm 0.1$ in BVD-positive, and $8.6 \pm 0.1 \mathrm{~g} / \mathrm{dL}$ in BVD-negative animals, opposite to results described in Iraq (Alsaad et al., 2012). The variation between these results may be due to the age difference. In Iraq the study was performed in calves, but in the present study most of the cattle were above two years old and haemoglobin decreases with age. Ruginosu et al. (2010) mentioned $9.2 \pm$ $0.3 \mathrm{~g} / \mathrm{dL}$ haemoglobin in cows with genital infection, which reflects decreased values due to infection. Those results showed similar trend with history of abortion and retained placenta.

Lymphocyte counts were higher than the studies in Iran, where lymphocyte count was $60.8 \pm 2.5$ in BVD-positive, and $47.5 \pm 3.6 \%$ in BVD-negative animals. In both studies, cows positive to BVD showed more lymphocytes than the negative animals. Monocyte counts were also higher than the results of $4.8 \pm 2.2$ in BVD-positive and 4.5 $\pm 1.1 \%$ were detected in BVD-negative animals, in Iraqi cattle (Alsaad et al., 2012). The value in cattle with genital infection was $1.7 \pm 0.2 \%$, lower than these results (Ruginosu et al., 2010).

Neutrophil counts were lower than the study by Alsaad et al. (2012) and Ruginosu et al. (2010). Breed and stage of infection may be the cause of such variation. On the other hand, eosinophil count was higher than the other study at $9.7 \pm 0.1 \%$. Basophil 
count was lower in BVD-positive cows, whereas Alsaad et al. (2012) found the reverse pattern.

\section{Conclusions}

The overall sero-prevalence of BVD in Barisal division was 51.1\%. The highest prevalence was $82.8 \%$ in northern zone and lowest $(29.6 \%)$ in southern zone. Animals aged 3-5 years had higher prevalence than calves. Packed cell volume was higher in BVD-positive animals. Haemoglobin percentage was lower in BVD-negative animals. Further study is needed to investigate the disease in the study areas. It may be concluded that these data will provide valuable diagnostic indices for the cattle industry as well as for future research, which may help to control the disease.

\section{Conflict of interest statement}

The authors have no competing interests.

\section{Acknowledgments}

The author is grateful to the Faculty of Postgraduate studies, Patuakhali Science and Technology University for financial assistance, Department of Pathology and Parasitology, Patuakhali Science and Technology University and Department of Physiology, Bangladesh Agricultural University for their cooperation in conducting the research work.

\section{References}

Ahmad A, Rabbani M, Muhammad K, Shabbir MZ, Yaqub T, Munir K, Akhter F, Cepica A 2011: Prevalence of Bovine Viral Diarrhoea Virus Persistency in 12 Holstein Cattle Dairy Herds of Charlottetown, Canada. Pakistan Journal of Zoology 43 255-261.

Alsaad KM, Al-Obaidi, Hassan SD 2012: Clinical, Haematological and coagulation studies of bovine viral diarrhea in local Iraqi calves. Bulgarian Journal of Veterinary Medicine $\mathbf{1 5}$ $44-50$.

Archambault D, Beliveau C, Couture Y, Carman S 2000: Clinical response and immunomodulation following experimental challenge of calves with type 2 noncytopathogenic bovine viral diarrhea virus. Veterinary Research 31 215-227.

Gelfert CC 1991: Epidemiological investigation of the distribution of BVD virus among cattle in Turkey. Inaugural- Dissertation, Tieraerztliche Hochschule. Hannover. Germany.

Haider N, Rahman MS, Khan SU, Mikolon A, Gurley ES, Osmani MG, Shanta IS, Paul SK, L. Berry M, Islam A, Desmond J, Epstein JH, Daszak P, Azim T, Luby SP, Zeidner N, Rahman MZ 2013: Identification and epidemiology of a rare HoBi-like pestivirusstrain in Bangladesh. Transboundary and Emerging Diseases 61 193-198. 
Hamers C, Couvreur B, Dehan P, Letellier C, Lewalle P, Pastoret PP, Kerkhofs P 2000: Differences in experimental virulence of bovine viral diarrhoea viral strains isolated from haemorrhagic syndromes. Veterinary Journal 160 250-258.

ICTV (International Committee for the Taxonomy of Viruses) 2011: 'The positive sense single stranded RNA viruses', In AMQ King, MJ Adams, EB Carstens \& J Lefkowitz (eds.), Virus Taxonomy $9^{\text {th }}$ report, Elsevier Academic Press, London.

Jain NC 1986: Schalm's Veterinary Hematology. Lea and Febiger, Philadelphia, USA, $4^{\text {th }}$ Edition

Liebler-Tenorio EM, Ridpath JE, Neill JD 2002: Distribution of viral antigen and development of lesions after experimental infection with highly virulent bovine viral diarrhea virus type 2 in calves. American Journal Veterinary Research 63 1575-1584.

Lindberg AJ, Brownlie GJ, Gunn, Houe H, Moennig VH, Saatkamp W, Sandvik T, Valle PS 2006: The control of bovine viral diarrhea virus in Europe: today and in the future. Revue scientifique et technique Office International des Epizootics 25 961-979.

Lucero JP, Celedon MO, Aguilera M, Calisto A 2006: Molecular characterization of pestiviruses isolated from bovines in Chile. Veterinary Microbiology 115 208-217.

Luzzago C, Piccinini R, Zepponi A, Zecconi A 1999: Study on prevalence of bovine viral diarrhoea virus (BVDV) antibodies in 29 Italian dairy herds with reproductive problems. Veterinary Microbiology 64 247-252.

Mishra N, Rajukumar K, Tiwari A, Nema RK, Behera SP, Satav JS, Dubey SC 2009: Prevalence of Bovine viral diarrhoea virus (BVDV) antibodies among sheep and goats in India. Tropical Animal Health and Production 41 1231-1239.

Rubaye AKMI, Hasso SA 2012: Detection of bovine viral diarrhea-mucosal disease (BVD$\mathrm{MD})$ in buffaloes and cows using ELISA. The Iraqi Journal of Veterinary Medicine $\mathbf{3 6}$ 45-50.

Ruginosu E, Creangă1 S, Sofroniel M, Anton A, Solcan G 2010: The hematologic profile of cattle withreproductive diseases. Cercetărigronomiceînmoldova xiiii 142.

Samad MA 1999: Detection of bovine virus diarrhea virus antibodies in cattle with an enzyme-linked immunosorbentassay in Bangladesh. Bangladesh Veterinary Journal 33 121-123.

Stoffregen B, Bolin SR, Ridpath JF and Pohlenz J 2000: Morphologic lesions in type 2 BVDVinfections experimentally induced by strain BVDV2-1373 recovered from a field case. Veterinary Microbiology 77 157-162.

Sudharshana KJ, Suresh KB, Rajasekha M 1999: Prevalence of bovine viral diarrhoea virus antibodies in India. Revue Scientifique et Technique Office Internationales Epizootics 18 667-671. 